\title{
Wpływ obróbki powierzchni przy użyciu zimnej plazmy na przyczepność powłoki galwanicznej do kompozytu grafitowego i jej przydatność w procesach lutowania miękkiego
}

\author{
The influence of cold plasma-surface modification on the grip \\ of the electroplating finish to graphite composite \\ and for its usefulness in soldering processes
}

\section{Streszczenie}

W artykule przedstawiono problematykę dotyczącą przygotowania powierzchni kompozytu grafitowego przed nałożeniem galwanicznej powłoki miedzianej i jej wpływ na proces lutowania miękkiego w połączeniach z materiałami metalicznymi. Na próbki z kompozytu grafitowego, którego powierzchnię przygotowano różnymi metodami, oraz w końcowej obróbce przy użyciu zimnej plazmy, wytworzonej w atmosferze argonu, naniesiono galwanicznie warstwę miedzi, a następnie wykonano badania przyczepności powłoki do podłoża. Wyniki te porównano z wcześniej przeprowadzonymi pomiarami wytrzymałościowymi złączy kompozytu z naniesioną powłoką miedzianą, lutowanych na miękko z elementami ze stopu aluminium PA38 (6060).

Słowa kluczowe: kompozyt grafitowy; lutowanie miękkie; powłoki galwaniczne; zimna plazma

\begin{abstract}
In the article issues concerning preparing the surface of graphite composite before putting the galvanic copper layer and its influence on the soldering process were described in connections with metallic materials. To samples of graphite composite, of which the area was prepared with different methods, and in final processing using cold plasma, produced in the atmosphere of argon, galvanic a layer of copper was put, and then a research on the grip of the layer was performed to base material. The results were compared with earlier conducted endurance measurements of connectors of composite with the copper layer, soldered on softly with elements of the alloy of PA38 aluminium (6060).
\end{abstract}

Keywords: graphite composite; soldering; galvanic coats; cold plasma

\begin{abstract}
Wstęp
Spajanie materiałów takich, jak ceramika, grafit i materiały kompozytowe na osnowie grafitu stanowi zwykle duży problem technologiczny. Połączenia te są zwykle wykonywane poprzez procesy lutowania wysokotemperaturowego w próżni, w których decydujący wpływ mają zjawiska o charakterze dyfuzyjnym [6]. Obserwując liczne doniesienia literaturowe mówiące o wpływie obróbki zimną plazmą na stan i aktywność powierzchni materiałów [3,7,8,11], które zostały przygotowane przy użyciu tej technologii, można przypuszczać, że może ona poprawić powierzchnię także dla potrzeb nakładania powłok galwanicznych. Połączenia materiałów wytworzonych na osnowie grafitu $z$ aluminium i jego stopami znajdują zastosowanie w urządzeniach przewodzących prąd elektryczny, dlatego też złącza muszą cechować się odpowiednią przewodnością
\end{abstract}

elektryczną i wytrzymałością mechaniczną. Dobrą przewodność elektryczną można uzyskać stosując połączenie metaliczne uzyskane w procesie lutowania miękkiego. Lutowanie grafitu w sposób bezpośredni jest jednak niemożliwe do wykonania z uwagi na brak jego zwilżalności lutami miękkimi $[9,10]$.

\section{Materiały użyte do badań}

W badaniach zastosowano materiał kompozytowy na bazie koksu pakowego z dodatkiem grafitu (spełniającego funkcję smaru) i $40 \%$ wag. ziaren Cu jako napełniacza, sklejonych żywicą wypaloną do węgla szklistego, dostarczonego przez firmę Carbo-Graf Sp. z o.o., z Raciborza.

Dr hab. inż. Zbigniew Zimniak, prof. PWr; prof. dr hab. inż. Zbigniew Mirski; mgr inż. Ireneusz Ciepacz; dr hab. inż. Kazimierz Granat prof. PWr; dr inż. Tomasz Wojdat - Politechnika Wrocławska.

Autor korespondencyjny/Corresponding author: zbigniew.zimniak@pwr.edu.pl 
Wyżej wymieniony materiał poddano obróbce przygotowania powierzchni, nałożono warstwę powłoki galwanicznej miedzianej, a następnie poddano badaniom przyczepności powłoki do podłoża metodą „pull-off” przy użyciu testera ELCOMETER 510, wg normy PN-EN ISO 4624:2004.

\section{Zakres badań}

Zrealizowano następujący zakres badań:

a) przygotowanie powierzchni materiału kompozytowego:

- odtłuszczanie ultradźwiękowe,

- aktywacja w bezwodniku chromowym;

b) pomiary zwilżalności powierzchni kompozytu grafitowego po każdym ze sposobów przygotowania powierzchni;

c) pomiary chropowatości powierzchni kompozytu grafitowego przed nałożeniem powłoki galwanicznej;

d) wstępne zarysowanie powierzchni przed nałożeniem warstwy galwanicznej za pomocy głowicy $10 \mathrm{~mm}$ testera ELCOMETER 510 [2];

e) obróbka powierzchni przy użyciu zimnej plazmy;

f) naniesienie galwanicznej powłoki miedzianej na kompozyt grafitowy;

g) pomiary przyczepności powłoki galwanicznej do powierzchni kompozytu grafitowego metodą zrywania powłoki (metoda pull-off);

h) opracowanie wyników i wnioski.

Przygotowanie powierzchni materiałów przed nałożeniem powłoki galwanicznej ma zasadnicze znaczenie dla jej przyczepności do podłoża, a w przypadku powłok stanowiących warstwy pośrednie w połączeniach lutowanych ważne też jest znaczne rozwinięcie powierzchni oraz usunięcie wszelkiego rodzaju pozostałości po obróbce strumieniowościernej. Do badań wytypowano następujące sposoby przygotowania powierzchni:

- obróbka szlifierska,

- obróbka strumieniowo-ścierna,

- obróbka chemiczna,

- obróbka przy użyciu zimnej plazmy w atmosferze argonu wcześniej przygotowanych podłoży.

\section{Przygotowanie powierzchni materiału kompozytowego}

Szlifowanie próbek przeprowadzono przy użyciu papieru ściernego o gradacji 180. Obróbkę strumieniowo-ścierną zrealizowano przy użyciu korundu o gradacji 30. Po obróbce
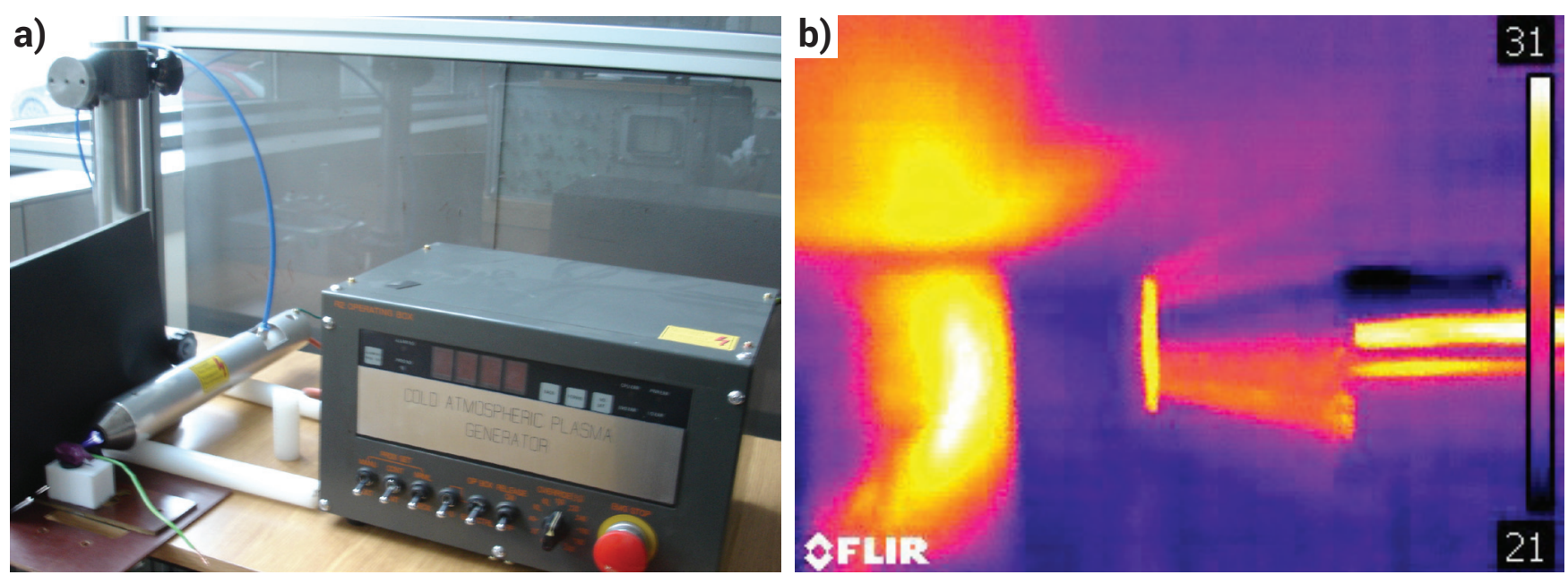

Rys. 1. Obróbka materiału kompozytowego przy użyciu zimnej plazmy: a) widok ogólny, b) pomiar temperatury plazmy kamerą termowizyjną Fig. 1. Treatment of a composite material using a cold plasma: a) general view, b) plasma temperature measurement with a thermal imager 
gdzie było to możliwe przy zastosowaniu analizatora energii powierzchni KRUSS DS. AHT-12 z oprogramowaniem HTM firmy Reetz GmbH (rys. 2).

Badania przy użyciu analizatora ATH12 firmy KRUSS możliwe były do wykonania tylko dla próbek szlifowanych i potwierdziły one wyniki testu kroplowego. Jedynie dla obróbki strumieniowo-ściernej z oddziaływaniem plazmy uzyskano zwilżanie w każdym teście.

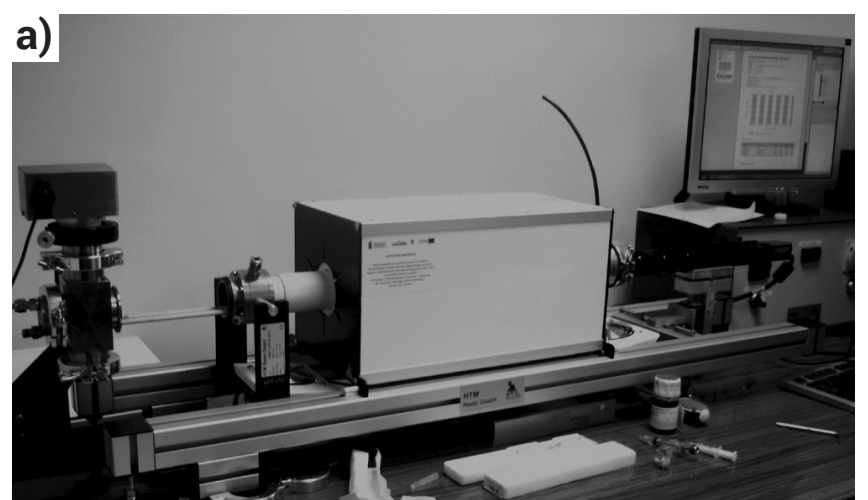

b)

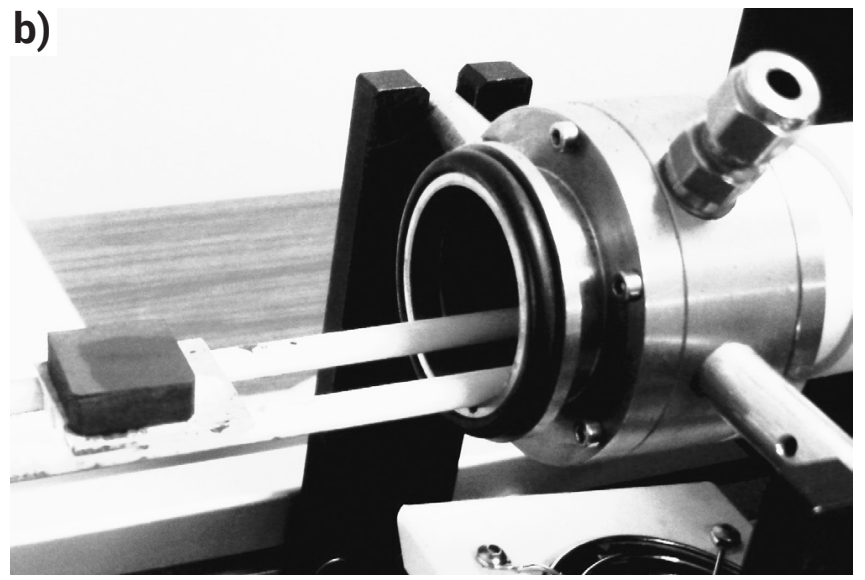

Rys. 2. Analizator energii powierzchniowej firmy KRUSS model $\operatorname{AHT12}(a, b)$

Fig. 2. Surface energy analyzer KRUSS model AHT12 (a, b)

\section{Pomiary chropowatości powierzchni}

Rodzaje obróbki powierzchni oraz otrzymane parametry chropowatości $R_{a}$ i $R_{z}$ przedstawiono w tablicy II. Zgodnie z oczekiwaniami, największą chropowatość uzyskano dla powierzchni przygotowanych poprzez obróbkę strumieniowościerną. Oddziaływanie plazmy spowodowało nieznaczne wygładzenie tych powierzchni. Podane wyniki są wartościami średnimi z trzech pomiarów.

\section{Pokrywanie próbek powłoką galwaniczną}

Do pokrywania próbek kompozytowych wybrano powłokę miedzianą. Proces pokrywania realizowano przy użyciu bezcyjankowej alkalicznej kąpieli do miedziowania SURTEC 864. Jest to kąpiel wytworzona na bazie pirofosforanów [5,12] (rys. 3).

Parametry pokrywania galwanicznego były następujące: - temperatura procesu: $60^{\circ} \mathrm{C}$,

- czas procesu: $60 \mathrm{~min}$,

- gęstość prądu: $3 \mathrm{~A} / \mathrm{dm}^{2}$.

Na rysunku 4 pokazano przekrój poprzeczny naniesionych powłok miedzianych na podłożu kompozytu grafitowego, przygotowanego przez szlifowanie i obróbkę strumieniowo-ścierną.
Tablica II. Wpływ rodzaju obróbki powierzchni na wielkość parametru chropowatości materiału kompozytowego

Table II. The influence of the surface treatment type on the roughness parameter of the composite material

\begin{tabular}{|c|c|c|}
\hline Rodzaj obróbki & $\mathbf{R}_{\mathbf{a}}[\boldsymbol{\mu m}]$ & $\mathbf{R}_{\mathbf{z}}[\boldsymbol{\mu} \mathbf{m}]$ \\
\hline Szlifowanie & 2,71 & 18,38 \\
\hline Szlifowanie+plazma & 2,62 & 17,14 \\
\hline Strumieniowo-ścierna & 9,49 & 52,09 \\
\hline Strumieniowo-ścierna+plazma & 7,56 & 45,83 \\
\hline
\end{tabular}

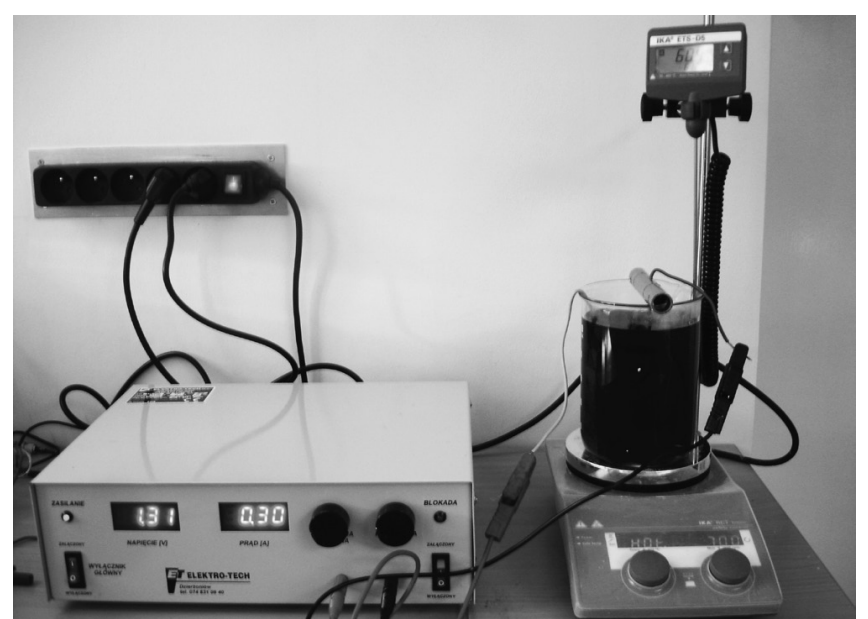

Rys. 3. Zestaw do nakładania miedzianej powłoki galwanicznej z kąpieli alkalicznej

Fig. 3. Stand for applying a copper galvanic coating from an alkaline bath
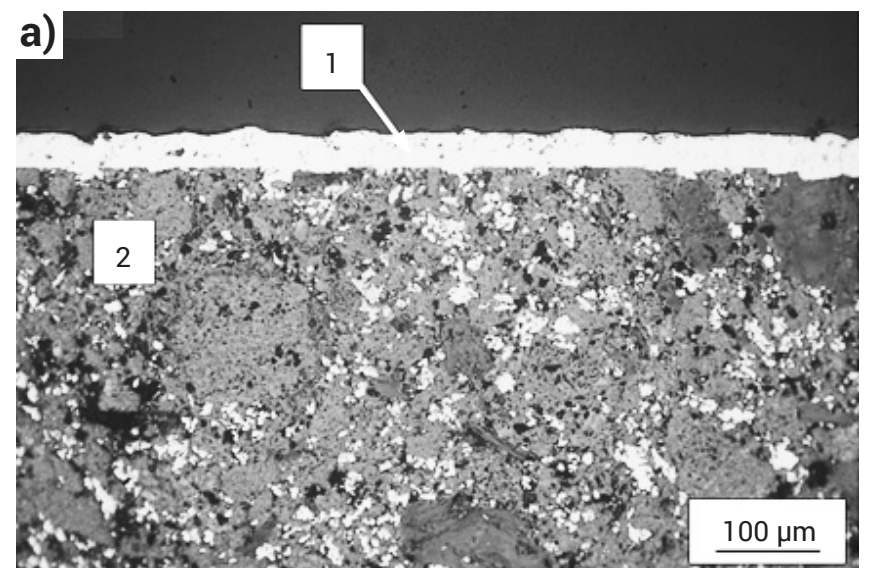

b)

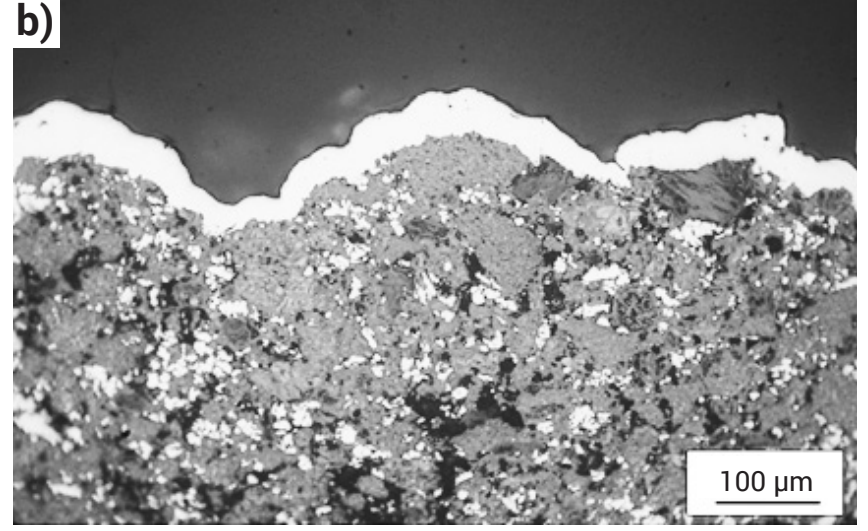

Rys. 4. Powłoki miedziane na podłożu kompozytu grafitowego, przygotowanego przez: a) szlifowanie, grubość powłoki $35 \mu \mathrm{m}$, b) obróbkę strumieniowo-ścierną, grubość powłoki $20 \div 50 \mu \mathrm{m}$; 1- powłoka $\mathrm{Cu}, 2$ - kompozyt grafitowy

Fig. 4. Copper coatings on a graphite composite substrate prepared by: a) grinding, $35 \mu \mathrm{m}$ coating thickness, b) abrasive blasting, coating thickness $20 \div 50 \mu \mathrm{m} ; 1-\mathrm{Cu}$ coating, 2 - graphite composite 


\section{Test przyczepności powłoki miedzianej do kompozytu grafitowego}

Test przyczepności nałożonych powłok miedzianych na powierzchnie przygotowanych $\mathrm{w}$ różny sposób próbek z kompozytu grafitowego przeprowadzono przy użyciu urządzenia ELCOMETER 510 z głowicą zdzierająca Ø10 mm (rys. 5).

Wstępnie zarysowano urządzeniem próbki nie pokryte, aby określić punkt odniesienia dla poszczególnych rodzajów podłoża [1].

Otrzymane wyniki zamieszczono w tablicy III, porównując je z wcześniej otrzymanymi wynikami ze statycznej próby ścinania połączeń lutowanych detali ze stopu aluminium PA38.

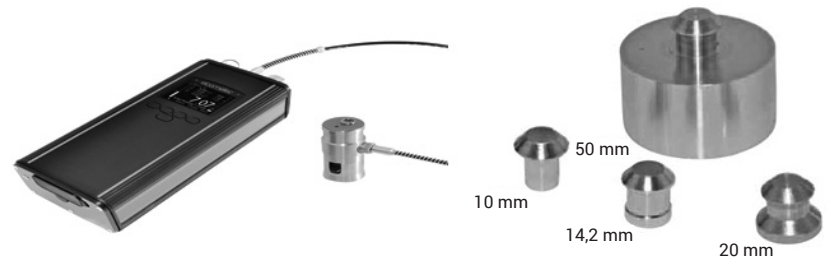

Rys. 5. Tester przyczepności powłok ELCOMETER 510 z głowicami pomiarowymi

Fig. 5. Adhesive tester ELCOMETER 510 for coatings with measuring warheads
Tablica III. Wyniki testu wytrzymałości na oderwanie powłoki galwanicznej od podłoża

Table III. Results of the test of resistance to peeling off the galvanic coating from the substrate

\begin{tabular}{|c|c|c|c|}
\hline Lp. & $\begin{array}{c}\text { Przygotowanie } \\
\text { powierzchni }\end{array}$ & $\begin{array}{c}\text { Naprężenie } \\
\text { potrzebne } \\
\text { do oderwania } \\
\text { powłoki Pz } \\
\text { [MPa] }\end{array}$ & $\begin{array}{c}\text { Wytrzymałośćc } \\
\mathbf{R}_{\mathrm{t}} \text { średnia } \\
\mathbf{z} \text { prób } \\
\text { statycznego } \\
\text { ścinania [MPa] }\end{array}$ \\
\hline 1. & szlifowanie & 7,0 & 6,3 \\
\hline 2. & szlifowanie+plazma & 9,6 & 9,4 \\
\hline 3. & $\begin{array}{c}\text { obróbka strumieniowo- } \\
\text {-ścierna }\end{array}$ & 14,8 & 12,5 \\
\hline 4. & $\begin{array}{c}\text { obróbka strumieniowo- } \\
\text {-ścierna+plazma }\end{array}$ & 22,8 & 17,6 \\
\hline
\end{tabular}

Charakter połączenia nałożonych powłok galwanicznych miedzianych na podłoże z kompozytu grafitowego obrabianego przez obróbkę szlifierską był przeważnie adhezyjny. Natomiast w przypadku próbek po obróbce strumieniowościernej i obróbką z użyciem zimnej plazmy, charakter połączenia był mieszany, tj. częściowo adhezyjny, a częściowo kohezyjny.

\section{Wnioski}

Na podstawie przeprowadzonych badań sformułowano następujące wnioski:

1. Wytwarzanie dobrej jakości połączeń kompozytu grafitowego ze stopem aluminium PA38 metodą lutowania miękkiego

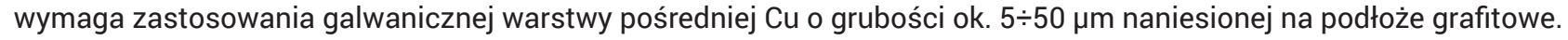

2. Decydujący wpływ na przyczepność naniesionych powłok miedzianych na podłoże z kompozytu grafitowego ma sposób przygotowania powierzchni materiału podłoża. Zastosowanie obróbki strumieniowo-ściernej powierzchni połączonej z obróbką zimną plazmą z zastosowaniem argonu, umożliwia prawie dwukrotny wzrost wytrzymałości na oderwanie powłoki od podłoża.

3. Zastosowanie dodatkowo obróbki zimną plazmą powierzchni pod pokrycie galwaniczne zwiększa w sposób znaczący przyczepność powłoki do podłoża.

\section{Literatura}

[1] Adams R.D.: Adhesive bonding Science, technology and application, Woodhead Publishing Limited 2005.

[2] Biestek T., Sękowski S.: Metody badań powłok metalowych, WNT, Warszawa 1973

[3] Borcia G., Chiper A., Rusu I.: Using a $\mathrm{He}+\mathrm{N}_{2}$ dielectric barrier discharge for the modification of polymer surface properties, Plasma sources Sci. Technol., 2006, 15, pp. 849-857.

[4] Stryczewska H.D.: Technologie zimnej plazmy, Wytwarzanie, modelowanie, zastosowania, Elektryka, 201, zeszyt 1 (217), rok LVII, Instytut Podstaw Elektrotechniki i Elektrotechnologii, Politechnika Lubelska, Lublin 2014.

[5] Campbell F., Frauenhofer J.A.: Surface Technology, 1976, 4, pp. 403-406.

[6] Chmielewski T.: Wykorzystanie energii kinetycznej tarcia i fali detonacyjnej do metalizacji ceramiki, Prace naukowe PW, Seria Mechanika, Zeszyt 232, Warszawa 2012

[7] Critchlow G.W., Brewis D. M.: Review of surface pretreatments for aluminium alloys, Int. J. Adhes. Adhes.,1996, 16, pp. 255-275.
[8] Iorio I. De, Leone C., Nele L., Tagliaferri V.: Plasma treatments of polymeric materials and Al alloy for adhesive bonding, J. Mater. Process Technol., 1997, 68, pp. 179-183.

[9] Mirski Z., Wojdat T., Stachowicz M.: Soldering of aluminium with copper and steel using intermediate layer $\mathrm{Zn}-\mathrm{Ni}$, Archives of Civil and Mechanical Engineering, 2015, vol. 15, nr 4, pp. 903-910.

[10] Mirski Z.,Wojdat T., Piwowarczyk T., Granat K., Derlukiewicz W., Ciepacz I., Jakubczyk A.: Lutowanie miękkie kompozytu grafitowego ze stopem aluminiowym PA38, Przegląd Spawalnictwa, 2016, vol. 88, nr 9, s. 50-55.

[11] Tioshifuji J., Katsumata T., Takikawa H., Sakakibara T. \& Shimizu I.: Cold arc- plasm jet on the atmospheric pressure for surface modification, Surface and Coating Tech. 2003, 171, pp. 302-306.

[12] Wiedemann R., Motta de Sillos R.: Technical Handbook, Surface Treatments, 2007, pp. 136-138. 